Received: Jan 28, 2019; Accepted: Feb 18, 2019; Published: Feb 23, 2019; Paper Id.: IJHRMRAPR2019010

\title{
INTRODUCTION
}

\section{Recruitment and Selection}

The growth and success of any organization hinges on the efficiency of the human resources. While the increased use of technology has made the work easier, the employees remain the single most important asset for an organisation. In this context, the process of recruitment and selection become a crucial human resource practice in the field of HRM. Recruitment is the process of attracting people with the right qualifications (as determined in the job analysis) to apply for the job (Ryan \& Tippins, 2004). Organisations may rely on media advertisements, campus recruitment, employment agencies, employee referrals, job fairs in order to recruit employees. Selection is the process of choosing from a group of applicants. The main goal of selection is to hire the candidate, who is most suitable for the job. Good HR selection process would help manage cost efficiency, minimizing labour turnover and increasing profitability of an organisation.

\section{Resume as a Tool of Selection}

Some selection instruments that can lead to the selection of an efficient workforce include interview, personality tests, aptitude tests, integrity tests, assessment centres etc. (Schmidt \& Hunter, 1998). One of the most common initial screening practices in the hiring process involves the use of resumes. Resumes are summaries of an applicant professional and educational background. Resumes are the currency of recruiting and have remained the sole determinant as to whether a candidate moves forward or not in the hiring process. They have an easy format to 
follow, highlight accomplishments and are quick to send to an in an email. Despite these strengths, there are some flaws in using resumes. Being self reported narrative descriptions of the candidates' past work with biases and selective memory of the candidate frequently results in a less-than-accurate description of what actually occurred. Resume fraud is another common problem that reduces the reliability of resumes as a selection tool.

Cole et al. (2004) found that the gender of recruiter and applicant affected evaluation of resume. They found that when women apply for "masculine" typed jobs and men apply for female typed jobs, there is more probability of being judged stereotypically. Therefore, other screening techniques should be used in addition to resumes for hiring process to be effective and efficient.

\section{Gender Bias in Selection of Resumes}

Gender stereotypes may play a role in resume selection. Men are commonly believed to exhibit "masculine" traits such as dominance, independence, and competitiveness, whereas women are believed to exhibit "feminine" traits such as dependence, nurturance, and communality (Martell, 1991). Two components (i. e., descriptive and prescriptive) of gender stereotyping have been identified (Eagly, 1987). The descriptive component consists of ideals regarding the characteristics possessed by a particular gender; however, the prescriptive component consists of beliefs about the characteristics that a gender should possess (Burgess \& Borgida, 1999). Attitudes and stereotypes have both conscious and unconscious (implicit) components; as people become socialized, their less-accepted attitudes do not vanish, but remain outside of conscious awareness (Wilson et al. 2000). Some studies also suggest that, depending upon a job's sex-typing; women may be undervalued, equally valued, or overvalued compared with men. Without information about the applicant's skills any available information, such as sex, will be used to estimate fit (Heilman, 1983). A woman, who applied for a maledominated job with no information about her competence, would likely be undervalued. According to Heilman et al. (1988), two conditions are necessary for over-evaluation to occur. First, a woman must be applying for or in an extremely male sex-typed job. Second, information must show that she is highly skilled for the job. They found that when job-related information was absent, men were rated significantly higher than women. Yet when skills were unknown, females were less favorably evaluated than males.

\section{Physical Attractiveness and Selection of Resumes}

Studies have found that attractive candidates have an advantage, and they are often considered more competent than candidates who are unattractive (Beehr \& Gilmore, 1982; Quereshi \& Kay, 1986). Subhani and Azmat (2012) concluded that factors like an applicant's appearance and dressing style affect the managers' decision to hire them and not just attractiveness. Dion et al.(1972) in their seminal work found that attractive people are always getting an edge in their lives and are given priority over the unattractive ones. But all these practices of biasness can put an organization into risk for applying unethical actions, so employers must be cautious. Despite this, there is reason to question whether physical attractiveness always is an advantage in the work world, particularly when the attractive individual is female. If a woman's attractiveness enhances the perception of femininity, it should exacerbate this presumed lack of fit. Thus, the more attractive a woman is, the less suitable she will be judged for occupying a job that is thought to require "male" characteristics. Cash et al. (1977) found a tendency for attractive women to be rated more favorably than unattractive ones for 'female' jobs. Thus, attractiveness appears to be a disadvantage for women job applicants when seeking positions believed to require predominantly masculine talents for success. Some research also indicates that people in positions with authority have a belief that women may be 'unequipped temperamentally' for management positions (Bowman et al., 
1965). Studies have also revealed that attractive women are penalized for their appearance when they seek managerial positions (Dipboye, et al. 1975). The findings are startling and contrary to what most of us would want the corporate world to be- as providing everyone a level playing field.

\section{REVIEW OF LITERATURE}

One of the most common biases occurring at workplace in recruitment decisions are on the basis of sex and physical attractiveness. In this context, Dipboye et al. (1975) in a sample of 30 male undergraduate college students and 30 male professional interviewers who rated bogus resumes found that attractive applicants were preferred to unattractive applicants and male applicants were more suitable than female applicants. A replication of this study was done by Dipboye, Arvey and Terpstra (1977) involving 110 college students (both male and female). The analysis of variance concluded similar findings, with main effects found for applicant sex, physical attractiveness, and qualifications. The researchers attributed discrimination in employment decisions to sex-role and physical attractiveness stereotypes. Heilman and Saruwatari (1979) explored the idea that the career opportunities of attractive women are hindered by their appearance and conducted an experiment to determine the effects of both appearance and sex on the evaluations of applicants for managerial and non- managerial positions. They found that attractiveness consistently proved to be an advantage for men but was an advantage for women only when seeking a non-managerial position. This was found to be the case in ratings of qualifications, recommendations for hiring, suggested starting salary, and rankings of hiring preferences.

Steinpreis et al. (1999) attempted to determine some of the factors that influence outside reviewers and search committee members when they are reviewing curricula vitae and concluded that both men and women were more likely to vote to hire a male job applicant than a female job applicant with an identical record. Masser and Abrams (2004) examined the consequences of hostile sexism for female applicants applying for managerial posts. Results revealed that higher hostile sexism was significantly associated with more negative evaluations of the female candidate and with lower recommendations that she be employed as a manager. Coleet al. (2004) examined the effect of recruiter and applicant gender on recruiters' evaluations of applicants' qualifications as reported on actual applicant resumes. They found those male recruiters' perceptions of applicants' work experiences did not differ depending on applicant gender. However, female recruiters perceived male applicants' resumes to report more work experiences than resumes of female applicants. Such studies indicate that gender and physical attractiveness bias are nowhere a thing of the past. They are as much prevalent today as they were before. What is more surprising is to see how both men and women show a clear bias against women as far as hiring decisions are concerned (Dipboye et al., 1977; Steinpreis et al., 1999). The present study thus aimed at seeing the effect of the gender and physical attractiveness of the applicant on evaluation of resumes. Following hypotheses were formulated based on previous research (Cole et al., 2004; Ruffle \& Shtudiner, 2010):

Hypothesis 1: Participants will rate male applicants more hireable for the job than female applicants.

Hypothesis 2: Participants will rate the attractive applicants as more hireable for the job than the unattractive applicants.

Hypothesis 3: The interaction between applicants' attractiveness and gender would have an effect on participants' assessment of the applicant's hireability. 
Hypothesis 3(a): Participants will rate the attractive male applicant as more hireable for the job than the unattractive male applicant.

Hypothesis 3(b): Participants will rate the attractive female applicant as more hireable for the job than the unattractive female applicant.

\section{METHODOLOGY}

A 2 X 2 factorial design was used in order to manipulate experimentally the gender of applicant (male versus female) and physical attractiveness (attractive versus unattractive). The gender of applicant was manipulated by presenting participants with the photograph of either a male or a female on the top right side of the resume, and by the name of the applicant. Physical appearance was manipulated by presenting participants with a photograph of an attractive male or female, or unattractive male or female. The photographs were selected on the basis of a pilot study. The 4 resumes were constructed by taking actual resumes and changing relevant details to suit the study design. All resumes were designed to be of a student who graduated in 2018. All additional information given in the resumes was held relatively constant like format of the resume, their caste (similar surnames), place from where they hailed (all from Delhi), and quality of the applicants in terms of their educational background (one each from Mathematics, Statistics, Commerce and Economics), college, number and quality of internships, positions of leadership, extra-curricular interests and achievements, social work, etc.. The similarity of resumes was confirmed through a pilot study. Male college students were brought in to an experimental set-up in which they were asked to evaluate 4 resumes each, with a passport size photograph of the applicant's face. Counterbalancing was used to prevent primacy and recency effect vis-a-vis the order of presentation of resumes. The experimental task was introduced as a study of recruitment decisions in which they were asked to evaluate 4 candidates who have applied for the position of Associate Research Analyst for Kepler Cannon, a global management consulting firm. The participant's willingness to hire a particular applicant was assessed using a three-item, 7-point hireability scale ranging from 1 (not at all likely) to 7 (extremely likely) adapted from Rudman and Glick (2001; alpha=.91). A demographic sheet was given then to the participant. This was followed by a series of open-ended questions regarding their decision making process and the factors that impacted their decision, particularly the photograph.

\section{Selection of Photographs}

About 10 photos of each of men and women were selected from publicly available online portals keeping with the design of the study (they all looked like young college graduates, North Indians, good quality of the photograph, etc.). 52 male undergraduate students rated each photograph on a scale of 1-10, where 10 denoted 'most attractive' and 1 'least attractive'. Two images each of males (mean= 5.35 and $\mathrm{SD}=2.55$ for most attractive male; mean= 3.85 and $\mathrm{SD}=2.37 \mathrm{for}$ least attractive male) and females (mean= 7.08 and $\mathrm{SD}=2.16$ for most attractive female; mean=3.77 and $\mathrm{SD}=2.17$ for least attractive female) receiving the highest and the lowest ratings on attractiveness were selected. $t$ test for independent means indicated that there was a significant difference on attractiveness for both females $(\mathrm{t}(50)=7.90$, $\mathrm{p}<.00001)$ and males $(t(50)=2.75, p=0.007)$. Passport size prints were taken out and attached to the resumes constructed.

\section{Participants}

111 male university undergraduates (mean age $=20.08$ years), recruited through convenience sampling successfully completed the experiment. All participants provided informed consent. 


\section{Procedure}

The participants were seated in the laboratory. After rapport formation and taking informed consent, they were given the requisite instructions. Each participant was given a job description, four resumes and the hire ability scale. Each participant received one resume of an attractive male, an unattractive male, an attractive female, and an unattractive female. No time limit was presented and the participant was free to take as much time as he required to go through each resume. Their queries were addressed. After they had filled the hire ability scale for the four applicants, they were then given a demographic sheet to fill. This was followed by a short interview that comprised of mostly open-ended questions that were asked in order to explore the decision making process of the participant like "what factors influenced you the most when reviewing the resumes", "I see that you have given the highest score to X. what about him/her stood out for you and led to your decision?" In order to carry out a manipulation check, the participants were asked to rate each of the four photographs on attractiveness, on a scale of 1-10. The participants were then debriefed and thanked for their participation.

\section{RESULTS AND ANALYSIS}

The obtained data was subjected to both quantitative analysis (using SPSS version 23) and qualitative analysis of the interview responses obtained. A $2 * 2$ factorial ANOVA was conducted to compare the main effects of gender and attractiveness, and the interaction effect between them, on resume assessment scores. Table 1 depicts the mean and standard deviation of the resume assessment scores for the 4 applicants.

Table 1: Descriptive Statistics

\begin{tabular}{|l|c|c|}
\hline \multicolumn{1}{|c|}{ Resume Assessment Score } & Mean & SD \\
\hline Male, low on attractiveness & 5.01 & 1.13 \\
\hline Male, high on attractiveness & 5.26 & 1.30 \\
\hline Female, low on attractiveness & 5.43 & 1.14 \\
\hline Female, high on attractiveness & 4.94 & 1.60 \\
\hline
\end{tabular}

As can be seen from Table 1, the most hireable candidate for the position of Associate Research Analyst for a global management consulting firm, in the present study was female, low on attractiveness, followed closely by male, high on attractiveness. Interestingly, the candidate considered the least hireable was female, high on attractiveness.

Table 2: Two way ANOVA with Gender and Attractiveness

\begin{tabular}{|l|c|c|c|c|}
\hline \multicolumn{1}{|c|}{ Source } & Df & MS & F & $\boldsymbol{p}$ \\
\hline Gender & 1 & 1.51 & 0.92 & 0.34 \\
\hline Attractiveness & 1 & 0.25 & 0.23 & 0.63 \\
\hline Gender*Attractiveness & 1 & 61.51 & 10.40 & 0.002 \\
\hline Error & 110 & 5.92 & & \\
\hline
\end{tabular}

As can be seen in Table 2, the main effect of gender was non-significant, $F(1,110)=0.92, p>0.05$. Thus Hypothesis 1 is rejected. The main effect of attractiveness was non-significant, $F(1,110)=0.23, p>0.05$. Thus Hypothesis 2 is also rejected. However, the interaction effect was significant, $F(1,110)=10.40, p<0.05$. This indicates that attractiveness of the applicants had different effects on resume assessment scores depending on gender of the applicants. Thus, Hypothesis 3 is accepted. 
Table 3: t Test for Dependent Samples to Compare Resume Assessment Scores between the Two Males and the Two Females

\begin{tabular}{|l|c|c|c|c|c|}
\hline & Mean & SD & T & df & Sig. 2 Tailed \\
\hline Male low on attractiveness & 5.01 & 1.13 & \multirow{2}{*}{1.58} & 110 & 0.12 \\
Male high on attractiveness & 5.26 & 1.30 & & & \multirow{2}{*}{0.006} \\
\hline Female low on attractiveness & 5.43 & 1.14 & 2.82 & 110 & 4.94 \\
Male low on attractiveness & 4.60 & & & \\
\hline
\end{tabular}

t-test for dependent samples was conducted to compare the resume assessment scores of the attractive male applicant and the unattractive male applicant which found no significant difference in the mean scores for the resume between the two-unattractive male applicant $(\mathrm{M}=5.01, \mathrm{SD}=1.13)$ and attractive male applicant $(\mathrm{M}=5.26, \mathrm{SD}=1.30)$; $t(110)=1.58, \mathrm{p}>0.12$. These results suggest that the attractive male applicant was not considered any more hireable than the unattractive male applicant as depicted in Table 3. Thus, hypothesis 3(a) is rejected. No significant difference in the scores for unattractive female applicant $(M=5.43, S D=1.14)$ and attractive female applicant $(M=4.94, S D=1.60) ; t(110)=2.82$, $\mathrm{p}<0.01$ ) was found. These results suggest that the unattractive female applicant was considered more hireable for the job than the attractive female applicant as depicted in Table 3. Thus hypothesis 3(b) is rejected. To summarise, results show that attractiveness among males did not have a significant effect on their hireability, but made the female more unsuitable. It appears that at least in the present sample of male raters, beauty is irrelevant for men, but beastly among women. A manipulation check for attractiveness was done using t-test dependent samples to assess whether the photographs of attractive candidates were indeed found to be attractive by the participants of the study. There was a significant difference $(\mathrm{t}(111)=7.94, \mathrm{p}<0.01)$ in the scores for attractiveness between the unattractive female $(\mathrm{M}=5.84, \mathrm{SD}=1.76)$ and the attractive female $(M=7.62, \mathrm{SD}=1.67)$ and between the unattractive male $(\mathrm{M}=5.81, \mathrm{SD}=1.57)$ and the attractive male $(\mathrm{M}=6.68, \mathrm{SD}=1.74,(t(111)=5.16, \mathrm{p}<0.01))$.

The analysis of interviews revealed that participants considered various factors while evaluating resumes including the academic GPAs, research papers published, extra-curricular activities, internships, technical and mathematical skills, format of resume, and social work done. They cited reasons such as how the attractive female looked casual and overly dressed, as someone who seemed amicable and friendly. The unattractive female, they noted, seemed serious and more studious. As for the attractive male, they stated that his smile was very energetic and confident. The unattractive male was perceived to be less-confident but his smile was reportedly seeming sincere.

\section{DISCUSSIONS}

The present study aimed at seeing the effect of the gender and physical attractiveness of the applicant on evaluation of resumes by male college students. Results showed that the main effect of gender was non-significant $(\mathrm{F}(1,110)=0.92, \mathrm{p}>0.05)$ implying that the participants did not find applicants of any particular gender as more hireable for the job than applicants of the other gender. This finding is congruent with the assumptions of the social role theory (Eagly 1987; Eagly et al. 2000) according to which gender stereotypes tend to be less relevant when other information that is important in an organizational context is presented. In the present study, the presence of role information, female applicants portrayed as leaders had equal opportunity of being hired as male applicants with the same credentials. The type of job description presented to the participants also helps explain why a bias towards a particular gender was not shown by the participants. The job of 'Associate Research Analyst' required both- the traditional 'male' and 'female' skills to be successful at it like 'obtain data from multiple sources, collate, analyse and synthesize information to develop reliable fact 
bases' (a typical male skill) as well as 'Excellent client management and engagement skills' (a typical female skill). The job profile was therefore not gender salient. Research has suggested that when applicants are presented with ambiguous credentials or background history, stereotypes are used to complete the unavailable information (Darley and Gross, 1983). By providing a resume that detailed on the required job relevant characteristics of each of the applicants, it is possible that less room was left for the automatic activation of the gender- related stereotypes in the present study. Further, it must be noted that gender is not the single most important factor that is considered while making hiring decisions. Of the various biodata elements, grade point average (GPA), academic achievement, work experience have been suggested as the most frequently used descriptors from which to infer characteristics about candidates' intellectual abilities as well as abilities needed to complete the job (Brown and Campion, 1994). Studies have indicated that extracurricular activities have also been a descriptor used and are of importance in the resume- screening process. The participants that constituted the current sample belonged to the age range of 18 -21 years, most of them studying in colleges across Delhi- NCR, belonged to primarily middle class with mostly college educated parents. Such a population generally has access to liberal discourses about gender equality and gender progressive values and are more likely to question the traditional gender role assignments. Concerns about social appropriateness are especially acute nowadays with regard to the equitable treatment of men and women. Further, the fact that the study was set in an institution that is known for its socially progressive and liberal ideologies might have heightened the sense of social desirability in the participants further encouraging them to act in a way, which may have been inconsistent with their real opinions.

In the current study, main effect of attractiveness was found to be non-significant, $(\mathrm{F}(1,110)=0.23, \mathrm{p}>0.05)$ indicating that the participants did not consider the attractive participants to be more hireable as compared to the unattractive applicants. According to Heilman and Saruwatari (1979) whether attractiveness will have a role in determining if an attractive applicant is hired for a job depends on the type of job manipulation used in a study. Therefore, for jobs such as, sales, in which physical attractiveness could conceivably be a job-relevant factor. This phenomenon might not have worked in the current study as the participants had to select applicants for the position of Associate research Analyst, a job that requires one to be good with numerical and communication abilities. Attractiveness was therefore not a job relevant characteristic in the current study as can be seen from a participants who said that, 'it is not a job for an airhostess or Mr or Ms. India, so it has nothing to do with the face'. Further, it has been shown in previous researches that applicant attractiveness has a positive effect on the attribution of some general (not job-specific) characteristics (Dion et al., 1972). Therefore, there is no particular reason to expect the type of job for which the applicant is being hired for to affect one's job related attributions for an applicant and therefore affect one's decisions to hire. Subhani and Azmat (2012) have further concluded that decision of hiring managers does not necessarily based upon the physical attractiveness but is influenced by various other factors which include candidate's educational qualifications, previous experience etc. Some researchers have also suggested that the attractiveness bias may be less pronounced in Asian societies as compared to the Western societies (Wheeler and Kim, 1997). Attractiveness bias may be mitigated in an Asian culture since physical attractiveness has been shown to be less important (Dion et al., 1990), especially for men.

It is interesting to see a significant interaction effect of gender and attractiveness $(F(1,110)=10.40, p<0.05)$, which indicated that attractiveness of the applicants had different effects on resume assessment scores depending on gender of the applicants with no significant difference between the hire ability ratings of the two male participants but less attractive female preferred over attractive female. Since attractiveness overall was not found to be a significant determinant in hiring decision in the current study, it could be for the same reasons that an attractive male applicant did not get any 
edge over an unattractive male candidate for selection to a job. Turner et al., (2016) have highlighted the possibility of male same-gender discrimination based on attractiveness in the organizational world. Male recruiters who are recruiting male applicants may hold thoughts of prejudice or discriminating behaviours against a perceived attractive male applicant, since they believe that this male applicant will later compete with him for important organizational outcomes and may perhaps get an edge over him because of his attractiveness. Such a bias operates implicitly and thus is not reflected as an overt discrimination. Studies have suggested that attractiveness might not always be advantageous and could in fact have negative effects as evidenced in the 'Beauty is beast' effect (Heilman and Saruwatari, 1979). Previous studies have shown women's attractiveness only increases the likelihood of their being hired for a female-typed job or a non-managerial position (Heilman \& Stopeck, 1985). These findings are explained in terms of an incongruity between a person's attributes and the perceived job requirements- the lack-of-fit modelas given by Heilman (1983). A woman's attractiveness enhances the perception of femininity and therefore exacerbates this presumed lack of fit (Dipboye et al., 1977). When women are particularly attractive, this highlights their femininity, which may reinforce the stereotype that women will not display the agentic characteristics needed for male-typed jobs. The relationship was negative for women, implying that attractive women are seen as less agentic (and thus a worse fit) for male-typed jobs (Paustian-Underdahl \& Walker, 2015). The participants pointed that the unattractive female applicant 'was serious looking; she was more fit for the job'. Her photograph may have brought out certain male characteristics like self-confidence, directness, control, and dynamism, as well as certain female attributes like warmth, expressiveness (Rosenkrantz et al., 1968). The combination of these traits inferred from the unattractive female applicant photograph perhaps made her attributes more congruent to the job requirements. The results obtained in the current study can also be explained on the basis of Tversky's (1972) elimination by aspect model of decision making. He has proposed an iterative elimination process, in which an aspect is selected and alternatives that do not include this aspect are eliminated. This covert process of elimination continues until one alternative remains, which becomes the chosen alternative. Such a process of choice behaviour can be applied directly to hiring and promotion decisions. Because of the importance of good performance to organizational effectiveness, it is believed that that performance-related information is the first aspect chosen in the decision process, a second aspect will be chosen to evaluate these candidates further, and physical attractiveness is a probable choice as this second aspect. Thus, this model shows how one's level of previous performance is in itself valued as a quality over one's level of attractiveness.

\section{LIMITATIONS AND FUTURE DIRECTIONS}

Since resume screening is only the initial stage in the selection process, the results are only indicative of the initial phase of selection. The use of student recruiters rather than actual decision makers as research subjects raises the issue of whether their judgements can accurately assess the impact of attractiveness bias on employee- selection decisions. The study included only male participants and therefore the results cannot be generalised to the female population, and the real-world organizational setting. Further research can be conducted to investigate the gender and attractiveness bias in various employment situations and under circumstances that resemble as closely as possible the hiring process of the HRM specialist. Additional research might be directed towards different jobs- jobs at different levels in the job hierarchy, sex typed, non-sex typed jobs, etc. and research can look at whether the attractiveness and gender bias is operational in different cultures. 


\section{CONCLUSIONS}

The interaction effects for gender and physical attractiveness indicate that organisations must remain cautious, so that they do not let their biases influence the hiring decisions. The names of the applicants must be removed while presenting the resume so that the applicant gender cannot be guessed. Further, photographs must not be attached. A system of blind resume evaluation must be followed. The 'beauty is beastly' effect found in the current study implies that women can enhance their perceived managerial qualities by reducing their perceived feminine attributes (Desrumaux et al., 2009). Since the sample characteristics (educated, liberal ideology) could have been responsible for a lack of gender bias, training programs aimed at imparting such information can help counter the biasness against a specific population in recruitment decisions (Turner et al., 2016).

\section{ACKNOWLEDGEMENTS}

The authors appreciate the help of Ms. Sudha Sashwati throughout the research, especially in data analysis and are also grateful to the students in the Psychology Honours course, Batch of 2019, Lady Shri Ram College for Women for their immense support in shaping the study.

\section{REFERENCES}

1. Beehr, T. A., \& Gilmore, D. C. (1982). Applicant attractiveness as a perceived job-relevant variable in selection of management trainees. Academy of Management Journal, 25, 607-617.

2. Burgess, D., \& Borgida, E. (1999). Who women are, who women should be: Descriptive and prescriptive gender stereotyping in sex discrimination. Psychology, Public Policy and Law, 5, 665-692.

3. Bowman, G. W., Worthy, N. B., \& Greyser, S. A. (1965). Are women executives people? Harvard Business Review, $43,164-178$.

4. Brown, B. K., \& Campion, M. A. (1994). Biodata phenomenology: Recruiters' perceptions and use of biographical information in résumé screening. Journal of Applied Psychology, 79, 897-908.

5. Cash, T. F., Gillen, B., \& Burns, D. S. (1977). Sexism and "beautyism" in personnel consultant decision making. Journal of Applied Psychology, 62, 301-310.

6. Cole, M. S., Feild, H. S., \& Giles, W. F. (2004). Interaction of recruiter and applicant gender in resume evaluation: A field study. Sex Roles, 51, 597-608.

7. Darley, J. M., \& Gross, P. H. (1983). A hypothesisconfirming bias in labelling effects. Journal of Personality and Social Psychology, 44, 20-33.

8. Desrumaux, P., Bosscher, S., \& Leoni, V. (2009). Effect of facial attractiveness, gender, and competence of applicants on job recruitment. Swiss Journal of Psychology, 68, 33-42.

9. Dion, K., Berscheid, E., \& Walster, E. (1972). What is beautiful is good. Journal of Personality and Social Psychology, 24, 285-290.

10. Dion, K. K., Pak, A. W., \&Dion, K. L. (1990). Stereotyping physical attractiveness: A sociocultural perspective. Journal of Cross Cultural Psychology, 21,158-179. 
11. Dipboye, R. L., Arvey, R. D., \& Terpstra, D. E. (1977). Sex and physical attractiveness of raters and applicants as determinants of resume evaluations. Journal of Applied Psychology, 62, 288-294.

12. Dipboye, R. L., Fromkin, H. L., \& Wiback, K. (1975). Relative importance of applicant sex, attractiveness, and scholastic standing in evaluation of job applicant resumes. Journal of Applied Psychology, 60, 39-43

13. Eagly, A. H. (1987). Sexdifferences in social behavior: A social-role interpretation. Hillsdale, NJ: Erlbaum

14. Eagly, A. H., Wood, W., \& Diekman, A. B. (2000). Social role theory of sex differences and similarities: A current appraisal. In T. Eckes \& H. M. Trautner (Eds.), The developmental social psychology of gender (123-174). Mahwah, NJ: Erlbaum

15. Heilman, M. E. (1983). Sex bias in work settings: The lack of fit model. Research in Organizational Behavior, 5, $269-298$.

16. Heilman, M. E., Martell, R. F., \& Simon, M. C. (1988). The vagaries of sex bias: Conditions regulating the undervaluation, equivaluation, and overvaluation of female job applicants. Organizational Behavior and Human Decision Processes, $41,98-110$.

17. Heilman, M. E., \& Saruwatari, L. R. (1979). When beauty is beastly: The effects of appearance and sex on evaluations of job applicants for managerial and nonmanagerial jobs. Organizational Behavior and Human Decision Processes, $23,360-372$.

18. Heilman, M. E., \& Stopeck, M. H. (1985b). Being attractive, advantage or disadvantage? Performance-based evaluations and recommended personnel actions as a function of appearance, sex, and job type. Organizational Behavior and Human Decision Processes, 35, 202-215

19. Martell, R. F. (1991). Sex bias at work: The effects of attentional and memory demands on performance ratings of men and women. Journal of Applied Social Psychology, 21, 1939-1960.

20. Masser, B. M., \&Abrams, D. (2004). Reinforcing the glass ceiling: The consequences of hostile sexism for female managerial candidates. Sex Roles.51,609-615.

21. Paustian-Underdahl, S. C., Walker, L. S., \& Woehr, D. J. (2014). Gender and perceptions of leadership effectiveness: A metaanalysis of contextual moderators. Journal of Applied Psychology, 99, 1129-1145.

22. Quereshi, M. Y., \& Kay, J. P. (1986). Physical appearance, age, and sex as determinants of reactions to resumes. Social Behavior and Personality, 14, 103-112.

23. Rosenkrantz, P. S., Bee, H., Vogel, S. R., \&Broverman, I. K. (1968). Sexrole stereotypes and self-concepts in college students. Journal of Consulting and Clinical Psychology, 32, 287-295.

24. Rudman, L. A., \& Glick, P. (2001). Prescriptive gender stereotypes and backlash toward agentic women. Journal of Social Issues, 57, 743-762

25. Ruffle, B. J., \& Shtudiner, Z. (2010). Are good-looking people more employable? Discussion paper no. 10-06. Ben-Gurion University, Economics Department, Israel.

26. Ryan, A. M., \& Tippins, N. T. (2004). Attracting and selecting: What psychological research tells us. Human Resource Management, 43, 305-318.

27. Schmidt, F. L., \& Hunter, J. E. (1998). The validity and utility of selection methods in personnel psychology: Practical and theoretical implications of 85 years of research findings. Psychological Bulletin, 124, 262-274.

28. Subhani, M. I. (2012). Impact of Physical attractiveness on selection and recruitment process. International Journal of Accounting and Finance. Retrieved from http://mpra.ub.uni-muenchen.de/id/eprint/39104 

Attractiveness on Resume Evaluation

29. Steinpreis, R. E., Anders, K. A., \& Ritzke, D. (1999). The impact of gender on the review of the CVs of job applicants and tenure candidates: A national empirical study. Sex Roles, 41, 509-528.

30. Turner, S. L., Willman, S. C., \& Wright, R. R. (2016). The beautiful and the damned: Exploring the negative side of masculine attractiveness in hiring situations. URJHS, 15. Retrieved from: http://www.kon.org/urc/v15/turner.html

31. Tversky, A. (1972). Elimination by aspects: A theory of choice. Psychological Review, 79, 281-299.

32. Wheeler, L., \& Kim, Y. (1997). What is beautiful is culturally good: The physical attractiveness stereotype has different content in collectivist cultures. Personality and Social Psychology Bulletin, 23,795-800.

33. Wilson, T. D., Lindsey. S., \& Schooler, T. Y. (2000). A model of dual attitudes. Psychol. Rev. 107, 101-126. 
